\title{
Potential of molecular targeted therapy of HER-2 and COX-2 for invasive transitional cell carcinoma of the urinary bladder
}

\author{
KATSUYA NARUSE $^{1}$, YOSHIAKI YAMADA ${ }^{1}$, KOGENTA NAKAMURA $^{1}$, SHIGEYUKI AOKI ${ }^{1}$, \\ TOMOHIRO TAKI $^{1}$, KENJI ZENNAMI ${ }^{1}$, REMI KATSUDA ${ }^{1}$, MASAHITO WATANABE $^{1}$, \\ GENYA NISHIKAWA ${ }^{1}$, YOUKO ITOH ${ }^{1}$, KENJI MITSUI ${ }^{3}$, HATSUKI HIBI ${ }^{2}$ and NOBUAKI HONDA ${ }^{1}$ \\ ${ }^{1}$ Department of Urology, Aichi Medical University School of Medicine; ${ }^{2}$ Division of Urology, \\ Kyouritsu General Hospital; ${ }^{3}$ Division of Urology, Tokoname Municipal Hospital, Aichi, Japan
}

Received December 11, 2009; Accepted February 22, 2010

DOI: 10.3892/or_00000798

\begin{abstract}
Expression of HER-2 and COX-2 was determined to assess the potential of molecular-targeted therapy against human epidermal growth factor receptor-2 (HER-2) and cyclooxygenase-2 (COX-2) for the treatment of invasive bladder cancer. The subjects were 46 patients who attended Aichi Medical University Hospital between January 2001 and August 2008, underwent total cystectomy with a diagnosis of M0 bladder cancer, and received a pathological diagnosis of invasive transitional cell carcinoma of the urinary bladder (pT2-pT4). Expression of HER-2 and COX-2 was determined by immunohistochemical staining, and the results were interpreted by two pathologists by classifying HER-2 expression into four grades, and considering COX-2 positive when $10 \%$ or more of the tumor cells were stained. In HER-2 immunostaining, 10 subjects $(21.7 \%)$ were positive, all of whom had a Grade 3 tumor. Staging classification identified 2 subjects $(2 / 22,9.1 \%)$ with pT2 stage, $3(3 / 16,18.8 \%)$ pT3 stage, and $5(5 / 8,62.5 \%)$ pT4 stage. There was a correlation between HER-2 positivity and tumor stage $(\mathrm{P}=0.007)$. Lymph node metastasis was detected in 13 subjects, 3 of them $(3 / 8,37.5 \%)$ with $\mathrm{pN} 2$ metastasis were HER-2 positive. The 5-year cause-specific survival rate was $51.4 \%$ for HER-2-positive subjects and $83.4 \%$ for HER2-negative subjects. The outcome was poorer in HER-2positive subjects, but the difference in survival rate was not statistically significant $(\mathrm{P}=0.218)$. In $\mathrm{COX}-2$ immunostaining, 27 subjects $(58.7 \%)$ were found to be positive. Three $(3 / 4$, $75.0 \%)$ showed a Grade 2 tumor and $24(24 / 42,57.1 \%)$ a Grade 3 tumor. Staging classification identified 13 subjects $(13 / 22,59.1 \%)$ with pT2 stage, $9(9 / 16,56.3 \%)$ pT3 stage,
\end{abstract}

Correspondence to: Dr Yoshiaki Yamada, Department of Urology, Aichi Medical University School of Medicine, Nagakute, Aichi 480-1195, Japan

E-mail: yy1124@aichi-med-u.ac.jp

Key words: invasive bladder carcinoma, immunohistochemistry, HER-2, cyclooxygenase-2, molecular targeted therapy and $5(5 / 8,62.5 \%)$ pT4 stage. There was no correlation between COX-2 positivity and tumor grade or stage $(\mathrm{P}=0.488$ and 0.089 , respectively). Classification by the extent of lymph node metastasis revealed that 6 subjects $(6 / 8,75.0 \%)$ with pN2 were COX-2 positive. There was a correlation between COX-2 positivity and the extent ( $\mathrm{pN} 1$ or $\mathrm{pN} 2)$ of lymph node metastasis $(\mathrm{P}=0.008)$. The 5-year cause-specific survival rate was $84.0 \%$ for COX-2-positive subjects and $71.7 \%$ for COX-2-negative subjects. However, the difference in survival rate was not significant $(\mathrm{P}=0.407)$. Seven subjects $(7 / 46$, $15.2 \%$ ) were positive for both HER-2 and COX-2, and there was no statistically significant correlation between the status of HER-2 expression and that of COX-2 expression $(\mathrm{P}=0.2195)$. The present study failed to show any association between HER-2 or COX-2 positivity and outcome in subjects with invasive bladder cancer. However, HER-2-positive subjects tended to have a poorer outcome. This finding suggests that molecular-targeted therapy against HER-2 could be an effective therapy. Further studies involving a larger number of subjects are required.

\section{Introduction}

At present, total cystectomy is the standard therapy for nonmetastatic invasive bladder cancer. However, although the cause-specific survival rate is as high as about $70 \%$ in patients with invasion of the muscular coat of the urinary bladder (pT2), some patients have a poor outcome; the rate is about $30-40 \%$ in patients with invasion of the surrounding adipose tissue (pT3), and about $20 \%$ in patients with lymph node metastases. Analysis of the pattern of recurrence after total cystectomy revealed that many of the recurrences were distant metastases and that local recurrence accounted for about $10 \%$ (1). Therefore, to improve the treatment outcome of total cystectomy, it is more important to eradicate micrometastases that cannot be detected by imaging than to perform local therapy with curative intent. Surgical resection alone is not sufficient in patients with invasive bladder cancer with extension beyond the bladder wall or with lymph node metastasis, and additional therapy is required for such patients.

Unresectable or metastatic progressive bladder cancer is generally treated by combination chemotherapy with anticancer drugs. The typical chemotherapy regimen is M-VAC 
Table I. Patient characteristics stratified by HER-2 and COX-2 IHC staining results.

\begin{tabular}{|c|c|c|c|c|c|c|c|}
\hline & Total & $\begin{array}{l}\text { HER-2 } \\
\text { positive }\end{array}$ & $\begin{array}{l}\text { HER-2 } \\
\text { negative }\end{array}$ & P-value & $\begin{array}{l}\text { COX-2 } \\
\text { positive }\end{array}$ & $\begin{array}{l}\text { COX-2 } \\
\text { negative }\end{array}$ & P-value \\
\hline \multicolumn{8}{|l|}{ Characteristic } \\
\hline No. of patiants (\%) & 46 & $10 / 46(21.7)$ & $36 / 46(78.3)$ & & $27 / 46(58.7)$ & $19 / 46(41.3)$ & \\
\hline No. of deaths & 8 & 3 & 5 & & 3 & 5 & \\
\hline Gender, $\mathrm{M} / \mathrm{F}$ & $38 / 8$ & $9 / 1$ & $29 / 7$ & & $22 / 5$ & $16 / 3$ & \\
\hline \multicolumn{8}{|l|}{ Age, (years) } \\
\hline Mean (SD) & $65 \quad(8.45)$ & $65 \quad(7.79)$ & $(8.72)$ & 0.989 & $(9.93)$ & $(6.87)$ & 0.378 \\
\hline Median (range) & $64(47-82)$ & $64 \quad(55-82)$ & $64 \quad(47-79)$ & & $65 \quad(47-82)$ & $62 \quad(52-79)$ & \\
\hline \multicolumn{8}{|l|}{$\begin{array}{l}\text { Follow-up period, } \\
\text { (months) }\end{array}$} \\
\hline Mean (SD) & $34.4(30.7)$ & $22.5(22.6)$ & $37.7 \quad(32.0)$ & 0.305 & $30.0 \quad(31.6)$ & $40.5(29.0)$ & 0.108 \\
\hline Median (range) & $27(2-108)$ & $10.5(5-65)$ & $32.5(2-108)$ & & $14 \quad(2-108)$ & $41 \quad(2-89)$ & \\
\hline \multicolumn{8}{|l|}{ Grade, $(\%)$} \\
\hline $\mathrm{G} 2$ & $(8.6)$ & $0 / 4$ & $4 / 4 \quad(100)$ & & $(75)$ & $(25)$ & \\
\hline G3 & $42 \quad(91.3)$ & $10 / 42(23.8)$ & $32 / 42(76.2)$ & 0.270 & $24 / 42(57.1)$ & $18 / 42(42.9)$ & 0.488 \\
\hline \multicolumn{8}{|l|}{$\mathrm{T}$ classification, $(\%)$} \\
\hline $\mathrm{T} 2$ & $22(21.7)$ & $2 / 22$ & $20 / 22 \quad(91)$ & & $13 / 22(59.1)$ & $9 / 22 \quad(40.9)$ & \\
\hline $\mathrm{T} 3$ & $16 \quad(34.7)$ & $3 / 16 \quad(18.8)$ & $13 / 16(81.2)$ & & 9/16 (56.3) & $7 / 16 \quad(43.7)$ & \\
\hline $\mathrm{T} 4$ & $8 \quad(17.3)$ & $5 / 8 \quad(62.5)$ & $3 / 8(37.5)$ & 0.007 & $5 / 8(62.5)$ & $3 / 8 \quad(37.5)$ & 0.089 \\
\hline \multicolumn{8}{|l|}{$\mathrm{N}$ classification, $(\%)$} \\
\hline pN0 & 33 (71.7) & & & & & & \\
\hline pN1 & $5 \quad(10.8)$ & $0 / 33 \quad(0)$ & $5 / 33 \quad(100)$ & & $0 / 5$ & $(100)$ & \\
\hline pN2 & $8 \quad(13.3)$ & $3 / 8 \quad(37.5)$ & $5 / 8 \quad(62.5)$ & 0.118 & $(75)$ & $(25)$ & 0.008 \\
\hline
\end{tabular}

therapy, which has been the gold standard since Sternberg et al $(2,3)$ reported a response rate of $72 \%$ and a complete remission rate of $36 \%$. Subsequent research, however, showed that this therapy is not likely to provide long-term survival, achieving only a low response rate and a short duration of response. In addition, this therapy is performed mainly in elderly patients, imposing a great physical burden on them; as a result, dose reduction may be required, and accordingly there will be a problem of insufficient dose intensity. In addition, the standard therapy for M-VACresistant cancer has not yet been established. Furthermore, the results of a recent clinical study of chemotherapy with gemcitabine and cisplatin were by no means satisfactory (response rate, 49.4\%; 5-year-survival rate, 13.0\%) (4).

On the other hand, molecular targeted therapy for cancer utilizes drugs developed against changes in genes or molecules specific to cancer. It is advantageous in that these drugs can be administered in combination with currently available anticancer drugs and that this therapy can be performed as tailor-made therapy.

Vadlamudi et al (5) reported that human epidermal growth factor receptor-2 (HER-2 or HER-2/neu) regulated the expression of cyclooxygenase-2 (COX-2) in a study using a colorectal cancer cell line. Based on this study, we assessed the possible association between HER-2 and COX-2 expression to evaluate the potential of molecular-targeted therapy against HER-2 and COX-2 for the treatment of invasive bladder cancer, and also determined whether overexpression of these substances could predict the outcome of the disease by immunohistochemical staining (IHC) in a retrospective manner.

\section{Materials and methods}

Subjects. This study was conducted in 46 patients who attended Aichi Medical University Hospital between January 2001 and August 2008, underwent total cystectomy with a diagnosis of M0 bladder cancer, and received a pathological diagnosis of invasive transitional cell carcinoma of the urinary bladder (pT2-pT4). The last observation was performed on December 31, 2008. Histopathological grading was performed according to the World Health Organization classification system, (6) while primary tumors and lymph node metastases were assessed using the TMN classification system (7).

The present study was approved (approval No. 275) by the Institutional Review Board of Aichi Medical University. All subjects were fully informed before examination for the expression of HER-2 and COX-2 and gave their consent to the study. The baseline characteristics of the 46 subjects are presented in Table I. 

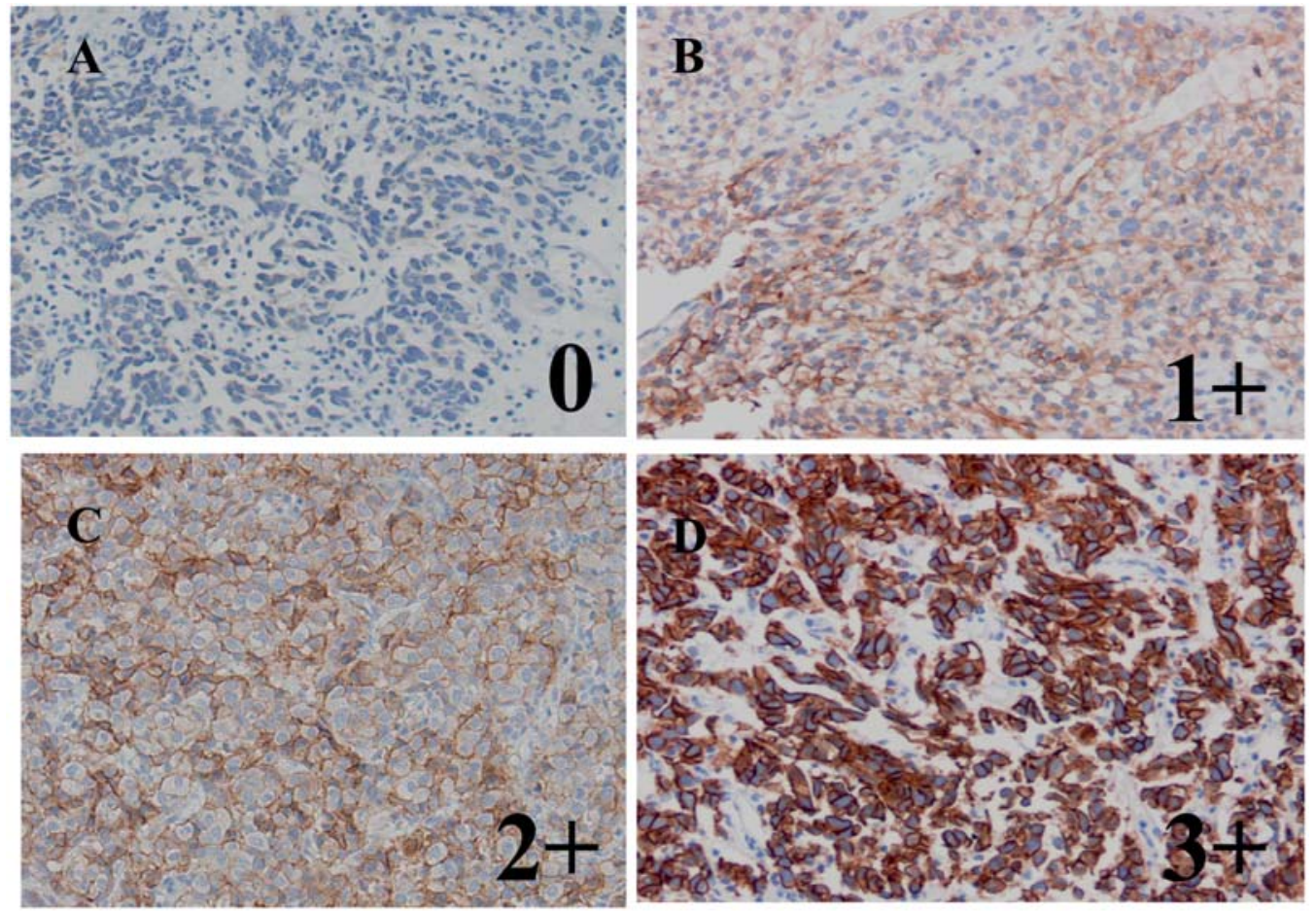

Figure 1. HER-2 expression detected by immunohistochemical staining using the Hercep Test kit in four primary tumors. (A) No staining or membrane was observed in $<10 \%$ of G2, pT2 tumor cells (HER-2 score 0), (x200). (B) Faint or barely perceptible membrane staining was detected in $>10 \%$ of G2, pT2 tumor cells: only part of their membrane of cells is stained (HER-2 score $1+),(x 200)$. (C) Weak to moderate, complete membrane staining was observed in $>10 \%$ of G3, pT4 tumor cells (HER-2 score $2+$ ), (x200). (D) Strong complete membrane staining was observed in $>10 \%$ of G3, pT4 tumor cells (HER-2 score $3+)$, (x200).

Immunohistochemistry method (IHC) and evaluation. Immunohistochemistry was performed with antibodies against human COX-2 and HER-2. Representative paraffin-embedded tumor tissue blocks were cut into $4-\mu \mathrm{m}$ slices and mounted on glass slides, followed by dewaxing in xylene, rehydrating in a graded series of alcohol, and rinsing in $0.01 \mathrm{M}$ Tris-buffer ( $\mathrm{pH} 7.3$ ).

HER-2 protein expression was stained for using a standardized Hercep Test kit. The primary antibody in this assay is an affinity-purified rabbit polyclonal antiserum raised against an intracellular epitope of the human HER-2 molecule (Specification Sheet: K5205, Dako, USA). The staining procedure includes an antigen retrieval step consisting of a 40-min incubation in pH 6.0 citrate buffer (Target Retrieval, Dako) in a $99^{\circ} \mathrm{C}$ water bath. Staining was performed using an automated staining apparatus for IHC (Autostainer, Dako) according to the manufacturer's guidelines. The slides were counterstained with haematoxylin. Each IHC experiment included a set of control slides. For the negative control, the primary antibody was replaced with an irrelevant, isotypematched antibody to control for non-specific binding of the secondary antibody reagent. The positive control slide consisted of sections of cell blocks of the three breast-cancer cell lines SKBR 3, MDA-MB-175 and MDA-MB-231, which express 2.4 million, 92000 and 22000 HER-2 receptor molecules by Scatchard analysis, respectively, and correspond to HER-2 scores of $3+, 1+$ and 0 , respectively, obtained by IHC. Histopathologic evaluation was done and staining results interpreted by two experienced pathologists and graded into four levels according to the classification of
Carter et al (8). We considered as in our previous report (9) the scores of $>3+$ positive. Each tissue specimen was examined by two experienced pathologists blinded to the stage and grade of the tumor on two separate occasions (Fig. 1).

COX-2 was detected using the labeled streptavidin biotin method. The endogenous peroxidase was inactivated with $3 \%$ hydrogen peroxide in absolute methanol for $30 \mathrm{~min}$ at room temperature. Antigen retrieval was performed using boiling citrate buffer ( $\mathrm{pH} \mathrm{6)}$ over 10 min and subsequently cooling to room temperature. Staining was performed using an automated staining apparatus for IHC (Autostainer) according to the manufacturer's guidelines. Non-specific reactions were suppressed with 5\% normal goat serum, rabbit anti-human monoclonal COX-2 antibody (Santa Cruz Biotechnology Inc.) diluted 1:20 in tris-bovine serum albumin, overnight at $4^{\circ} \mathrm{C}$. The sections were subsequently washed with phosphate buffer saline (PBS) and biotin-labeled mouse anti-rabbit $\operatorname{IgG}$ antibody was allowed to react at $37^{\circ} \mathrm{C}$ for 30 min, after which the specimen was washed in PBS, reacted with horseradish peroxidase-labeled streptavidin at $37^{\circ} \mathrm{C}$ for $30 \mathrm{~min}$. After washing, color was developed using diaminobenzidine $0.5 \%$ and hydrogen peroxide $0.01 \%$. The sections were counterstained with hematoxylin and mounted on slides. For negative controls the primary antibody was omitted from the samples. Inflammatory lymphoid tissue was used as positive control. Staining of the cytoplasm of the tumor cells $<10 \%$ was considered as a COX-2 negative result while $>10 \%$ cells was labeled as COX-2 positive. Each tissue specimen was examined by two experienced pathologists blinded to the stage and grade of the tumor on two separate occasions (Fig. 2). 


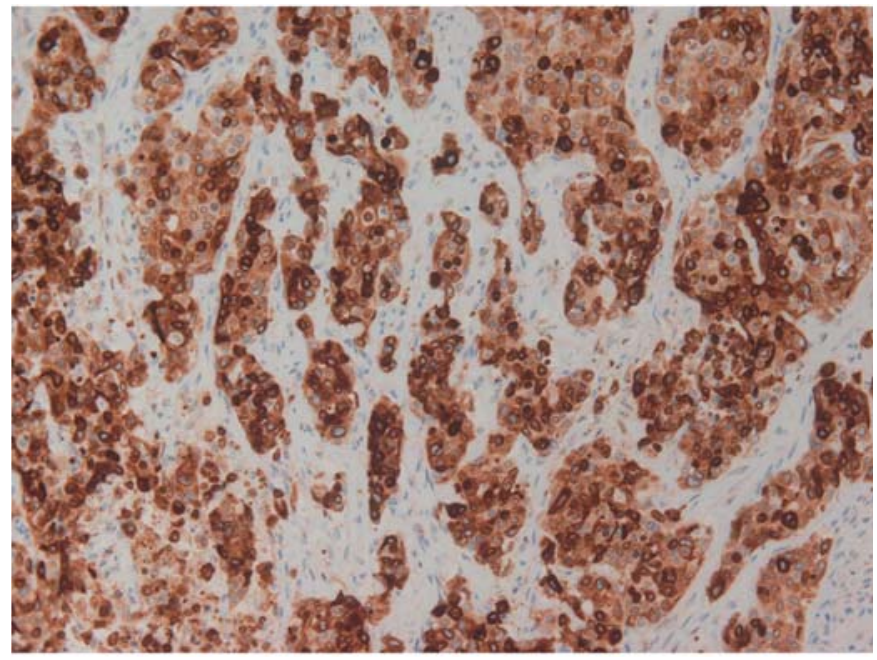

Figure 2. Strong staining was observed in $>95 \%$ of the cytoplasm of Grade 3 , pT3 tumor cells (COX-2 immunostaining positive), (x200).

Statistical analysis. Date from 46 patients were available for statistical evaluation, performed with Package for the Social Sciences (SPSS, Chicago, IL, USA) version 11.0 for Windows software. All clinical and pathological parameters were correlated with COX-2 and HER-2 staining results by MannWhitney $U$ test and $\chi^{2}$ test. Cumulative cause-specific survival times were estimated according to the method by Kaplan and Meier. Survival curves were compared by log-rank test. Probability values $<0.05$ were considered significant.

\section{Results}

HER-2 expression. HER-2 immunostaining showed a rating of 0 in 13 subjects $(28.2 \%), 1+$ in $18(39.1 \%), 2+$ in $5(10.8 \%)$ and $3+$ in $10(21.7 \%)$. At the rating of $3+, 10$ subjects $(21.7 \%)$ were classified as HER-2-positive. These 10 subjects had each a Grade 3 tumor. Staging classification revealed that many of the subjects with high stage were HER-2 positive $(\mathrm{P}=0.007)$. Classification by the extent of lymph node metastasis revealed that 3 subjects $(3 / 8,37.5 \%)$ with pN2 metastasis were HER-2-positive, and their primary lesions were also classified as $3+$ by HER-2 immunostaining (Table I).

The 5-year cause-specific survival rate was $51.4 \%$ in HER-2-positive subjects, while it was $83.4 \%$ in HER-2negative subjects. HER-2-positive subjects had a poorer outcome, but the difference was not statistically significant $(\mathrm{P}=0.218)($ Fig. 3).

COX-2 expression. In COX-2 immunostaining, 0-5\% staining was seen in 19 subjects $(41.3 \%), 6-10 \%$ in 0 and $>10 \%$ in 27 (58.7\%). COX-2 expression was identified by light brown staining of the cytoplasm of a tumor cell, with an unstained nucleus. No statistically significant difference in COX-2 expression was detected in subjects with different tumor grades or stages, while a correlation was seen between COX-2 expression and the extent of lymph node metastasis ( $\mathrm{pN} 1$ or $\mathrm{pN} 2)$. There were more COX-2-positive subjects with progression of lymph node metastasis $(\mathrm{P}=0.008)$ (Table I).

The 5-year cause-specific survival rate was $84.0 \%$ in COX-2-positive subjects, while it was $71.7 \%$ in COX-2negative subjects, but the difference was not statistically significant ( $\mathrm{P}=0.407)$ (Fig. 4).

HER-2 and COX-2. Seven patients (15.2\%) were positive for both HER-2 and COX-2. No statistically significant correlation was shown between the status of HER-2 expression and that of COX-2 expression $(\mathrm{P}=0.412)$ (Table II).

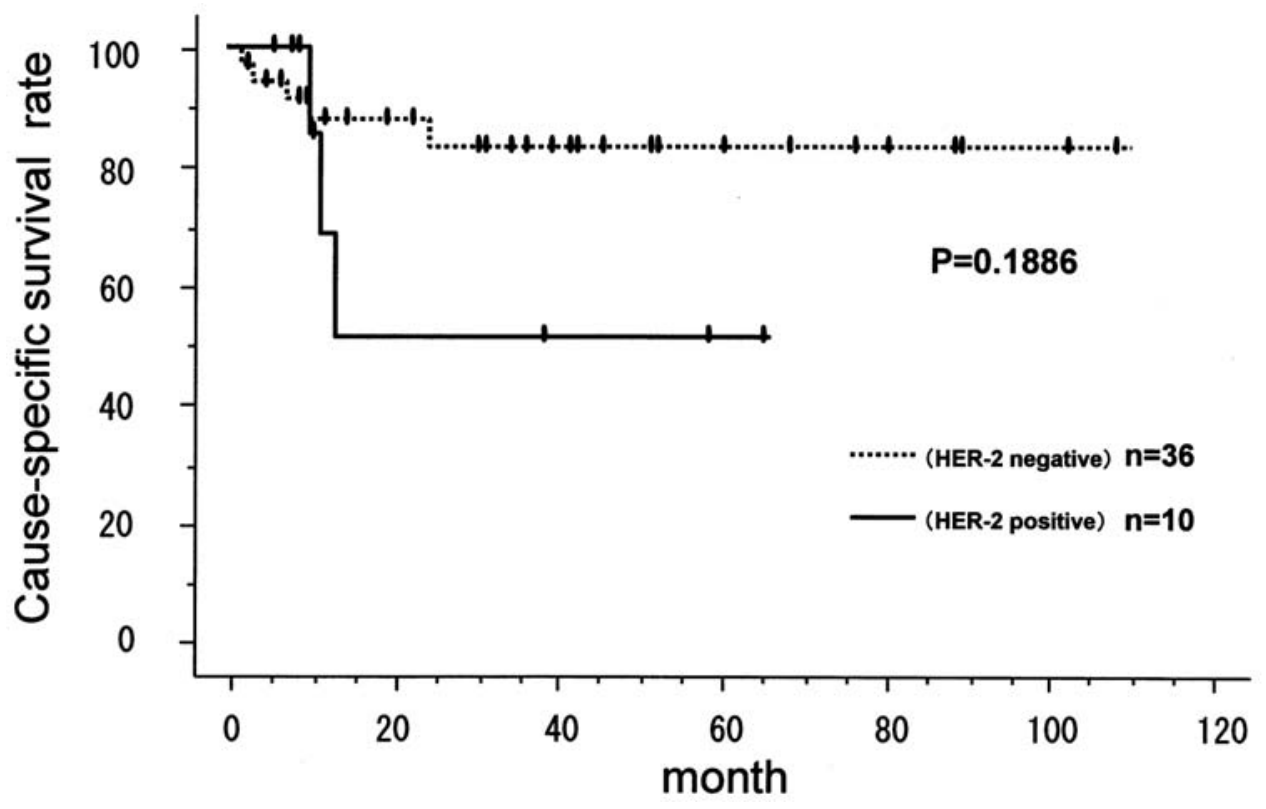

Figure 3. Cause-specific survival curves for HER-2-positive and HER-2-negative groups. The 5-year cause-specific survival rate was 51.4\% in HER-2positive subjects $(n=10)$, while it was $83.4 \%$ in HER-2-negative subjects $(n=36), P=0.218$. 


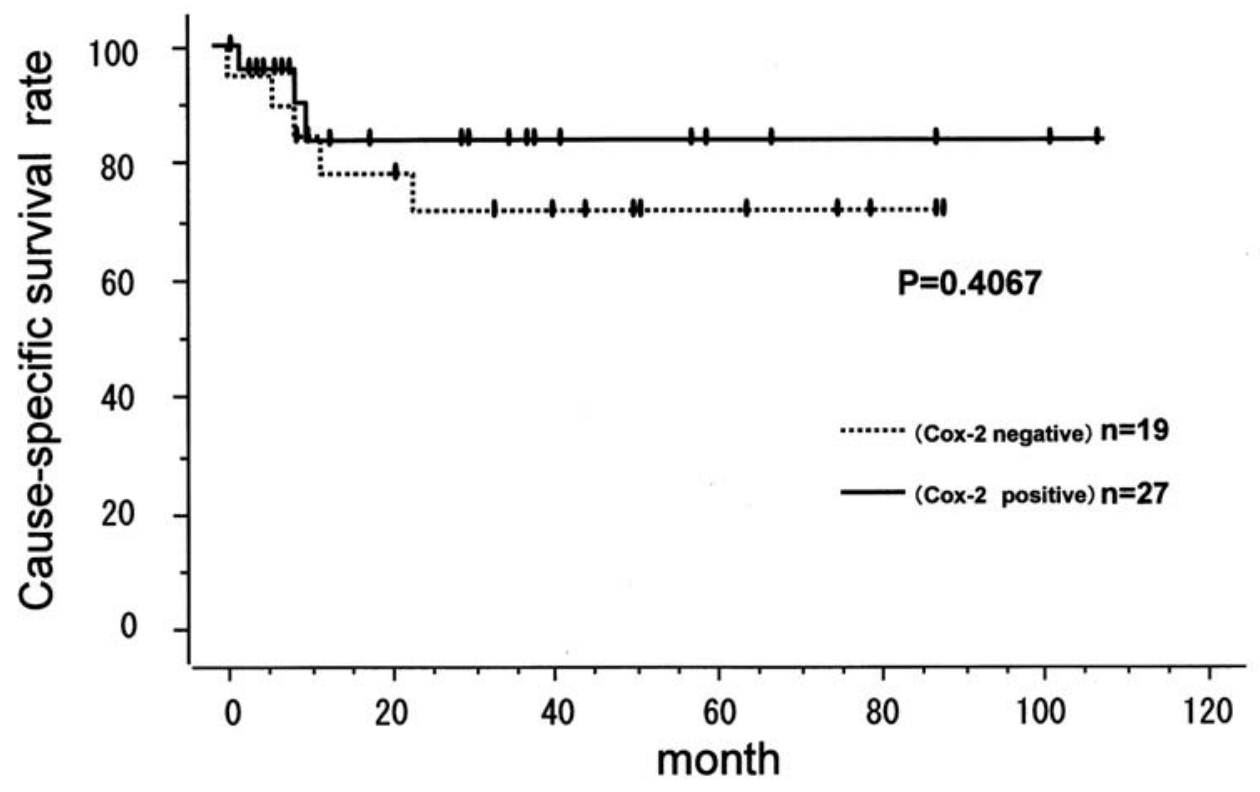

Figure 4. Cause-specific survival curves for COX-2-positive and COX-2-negative groups. The 5-year cause-specific survival rate was 84.0\% in COX-2positive subjects $(n=27)$, while it was $71.7 \%$ in COX-2-negative subjects $(n=19), P=0.407$.

Table II. Relationship between HER-2 and COX-2 IHC staining results.

\begin{tabular}{|c|c|c|c|}
\hline & HER-2+ & HER-2- & Total \\
\hline $\mathrm{COX}-2^{+}$ & 7 & 20 & 27 \\
\hline $\mathrm{COX}-2^{-}$ & 3 & 16 & 19 \\
\hline Total & 10 & 36 & $\begin{array}{c}46 \\
P=0.4118\end{array}$ \\
\hline
\end{tabular}

\section{Discussion}

HER-2 is a proto-oncogene located on chromosome 17q21. It encodes a protein with a molecular weight of $185 \mathrm{kDa}$ that has a receptor structure to penetrate the cell membrane. This protein is a tyrosine-kinase-type receptor on the surface of the cell membrane, and has an amino acid sequence resembling that of the epidermal growth factor receptor. It stimulates cell differentiation and proliferation through the ligand binding to the extracellular domain. Fundamental research has revealed that HER-2 overexpression induces cell tumorigenesis (transformation), showing greater aggressiveness. In normal tissues, HER-2 is only slightly distributed in the mammary glands, placenta, hepatocytes, bile duct, gastrointestinal tract, skin, genital organs and urinary tract; HER-2 expression is restricted in most normal tissues (10). Thus, molecular targeted therapy against HER-2 has interesting potential.

HER-2 has been considered a poor prognostic factor for breast cancer since Slamon et al (11) first reported the association between amplification of the HER-2 gene and poor-outcome breast cancer in 1987. HER-2-overexpressing breast cancer was shown to be refractory to hormone therapy (12), and thus trastuzumab therapy has been established for HER-2-overexpressing breast cancer (13).
It has been found that patients with HER-2-positive breast cancer can be more reliably selected by the use of gene amplification, rather than on the basis of antigen expression (14). It has been found that, in comparing HER-2 expression between IHC and fluorescent in situ hybridization (FISH), the dissociation between amplification and overexpression suggests the presence of point mutation, translocation or transcriptional up-regulation that leads to overexpression of the protein (15). Furthermore, since a breast cancer cell line is used as the positive control in the Hercep Test kit for IHC, whether the results of IHC can be applied to bladder cancer remains to be determined (16). We previously analyzed HER-2 expression by IHC and FISH in patients with invasive bladder cancer, and found that only IHC $3^{+}$was correlated with FISH. Based on this finding, IHC $3^{+}$patients alone were considered HER-2-positive in the present study (9).

In reports on HER-2 in patients with urothelial cancer, the frequency of HER-2 overexpression ranges between 12\% (17) and $71 \%$ (18). One study demonstrated that the frequency of overexpression correlated with tumor grade and stage (19), while another study stated that it did not (20). Therefore, the relationship between HER-2 overexpression and tumor grade or stage has not yet been established. In our study, the HER-2positive rate was $21.7 \%$ (10/46), and no correlation was shown between the HER-2-positive rate and tumor grade or the status of lymph node metastasis, while analysis by tumor stage revealed a significant correlation $(\mathrm{P}=0.007)$; the number of HER-2-positive patients increased with increase in the tumor stage. Assessment of the association between outcome and the status of HER-2 expression showed no statistically significant difference in outcome between HER-2-positive and HER-2-negative patients, but HER-2-positive patients tended to have a poorer outcome.

The importance of COX-2 has been most frequently studied in patients with large intestine cancer. Sheehan et al reported that the survival rate was significantly higher in patients with 
decreased COX-2 expression than in those with increased COX-2 expression (21). With regard to bladder cancer, a selective or non-selective oral COX-2-inhibitor given at a high dose was shown to reduce the incidence of bladder cancer in mice and rats (22). It was also reported that the risk of developing bladder cancer was reduced in patients receiving non-steroidal anti-inflammatory drugs (23).

In determining COX-2 expression, we considered a marked immune response detected in $10 \%$ or more of the tumor cells to be positive, and a weak or no immune response in the whole tumor to be negative, since we considered that visualization of a lesion obviously expressing COX-2 would clarify the effect of COX-2 on invasive bladder cancer. Some reports are available on COX-2 expression in patients with transitional cell carcinoma of the urinary bladder. One study showed a positive correlation between COX-2 expression and tumor grade and stage (24). Another study reported that low-grade and low-stage tumors showed higher COX enzyme activity than high-grade and high-stage tumors (25). Still another study revealed no association between COX-2 expression and tumor grade or stage (26). Thus, no conclusion has been reached as yet. In the present study, $58.7 \%$ (27/46) of all subjects were found to be COX-2 positive by immunostaining. Of the subjects with lymph node metastasis, $46.2 \%$ (6/13) were found to be COX-2 positive. No correlation was seen between the frequency of COX-2 expression and tumor grade or stage, while a significant correlation was noted between the frequency of COX-2 expression and the extent of lymph node metastasis ( $\mathrm{pN} 1$ or $\mathrm{pN} 2)$. However, we did not determine COX-2 expression in the pNO subjects in the present study. Therefore, it seems necessary to study the stainability for COX-2 in pN0 subjects, to assess the association between the extent of lymph node metastasis and COX-2 expression. Assessment of the association between outcome and the status of COX-2 expression revealed no significant difference. Shirahama et al (27) indicated that COX-2 expression was not a predictive factor for outcome. This finding is consistent with ours. On the other hand, Kim et al (28) stated that they were able to predict recurrence and disease progression, based on COX-2 expression, in patients with T1 or G3 bladder cancer. Another study revealed that COX-2 in combination with BCG was more useful than BCG alone (29). These findings suggest the necessity of investigation in cases of superficial bladder cancer.

Vadlamudi et al (5) demonstrated that HER-2 regulated COX-2 expression in a study using a colorectal cancer cell line. The results of our study were not consistent with this finding. In our study, only $15.2 \%(7 / 46)$ of the subjects were positive for both HER-2 and COX-2. Thus, no correlation was detected between HER-2-positive subjects and COX-2positive subjects. This finding was consistent with the results obtained by Eltze et al (30) from 153 patients who underwent total cystectomy.

In the present study, no association was found between HER-2 positivity and COX-2 positivity with respect to the outcome of subjects with invasive bladder cancer. However, since HER-2-positive subjects tended to have a poorer outcome, molecular-targeted therapy against HER-2 may be effective. Further studies in a larger number of patients are required.

\section{References}

1. Schuster TG, Smith DC and Montie JE: Pelvic recurrences postcystectomy: current treatment strategies. Semin Urol Oncol 19: 45-50, 2001.

2. Sternberg CN, Yagoda A, Scher HI, et al: Preliminary results of M-VAC (methotrexate, vinblastine, doxorubicin and cisplatin) for transitional cell carcinoma of the urothelium. J Urol 133: 403-407, 1985.

3. Sternberg CN, Yagoda A, Scher HI, et al: Methotrexate, vinblastine, doxorubicin and cisplatin for advanced transitional cell carcinoma of the urothelium. Efficacy and patterns of response and relapse. Cancer 64: 2448-2458, 1989.

4. Von der Maase H, Sengelov L, Roberts JT, et al: Long-term survival results of a randomized trial comparing gemcitabine plus cisplatin, with methotrexate, vinblastine, doxorubicin, plus cisplatin in patients with bladder cancer. J Clin Oncol 23: 4602-4608, 2005.

5. Vadlamudi R, Mandal M, Adam L, Steinbach G, Mendelsohn J and Kumar R: Regulation of cyclooxygenase-2 pathway by HER2 receptor. Oncogene 18: 305-314, 1999.

6. Epstein JI, Amin MB, Reuter VR and Mostofi FK: The World Health Organization/International Society of Urological Pathology consensus classification of urothelial (transitional cell) neoplasms of the urinary bladder. Am J Surg Pathol 22: 1435-1448, 1998

7. Sobin LH and Wittekind Ch (eds). TNM Classification of Malignant Tumors. 6th edition. Wiley-Liss, New York, pp199-202, 2002.

8. Carter P, Presta L, Gorman CM, et al: Humanization of an antip185HER2 antibody for human cancer therapy. Proc Natl Acad Sci USA 89: 4285-4289, 1992.

9. Matsubara H, Yamada Y, Naruse K, et al: Potential for HER-2/ neu molecular targeted therapy for invasive bladder carcinoma: comparative study of immunohistochemistry and fluorescent in situ hybridization. Oncol Rep 19: 57-63, 2008.

10. Press MF, Cordon-Cardo C and Slamon DJ: Expression of the HER-2/neu proto-oncogene in normal human adult and fetal tissues. Oncogene 5: 953-962, 1990.

11. Slamon DJ, Clark GM, Wong SG, Levin WJ, Ullrich A and McGuire WL: Human breast cancer: correlation of relapse and survival with amplification of the HER-2/neu oncogene. Science 235: 177-182, 1987.

12. Slamon DJ, Godolphin W, Jones LA, et al: Studies of the HER-2/ neu proto-oncogene in human breast and ovarian cancer. Science 244: 707-712, 1989.

13. Slamon DJ, Leyland-Jones B, Shak S, et al: Use of chemotherapy plus a monoclonal antibody against HER2 for metastatic breast cancer that overexpresses HER2. N Engl J Med 344: 783-792, 2001.

14. Dybdal N, Leiberman G, Anderson S, et al: Determination of HER2 gene amplification by fluorescence in situ hybridization and concordance with the clinical trials immunohistochemical assay in women with metastatic breast cancer evaluated for treatment with trastuzumab. Breast Cancer Res Treat 93: 3-11, 2005.

15. De Pinieux G, Colin D, Vincent-Salomon A, Couturier J, Amsellem-Ouazana D, Beuzeboc P and Vieillefond A: Confrontation of immunohistochemistry and fluorescence in situ hybridization for the assessment of HER-2/neu (c-erbB-2) status in urothelial carcinoma. Virchows Arch 444: 415-419, 2004.

16. Caner V, Turk NS, Duzcan F, et al: No strong association between HER-2/neu protein overexpression and gene amplification in high-grade invasive urothelial carcinomas. Pathol Oncol Res 14: 261-266, 2008.

17. Lipponen P, Eskelinen M, Syrjanen S, Tervahauta A and Syrjanen K: Use of immunohistochemically demonstrated cerbB-2 oncoprotein expression as a prognostic factor in transitional cell carcinoma of the urinary bladder. Eur Urol 20: 238-242, 1991.

18. Gandour-Edwards R, Lara PN Jr, Folkins AK, et al: Does HER 2/neu expression provide prognostic information in patients with advanced urothelial carcinoma? Cancer 95: 1009-1015, 2002.

19. Kolla SB, Seth A, Singh MK, Gupta NP, Hemal AK, Dogra PN and Kumar R: Prognostic significance of HER2/neu overexpression in patients with muscle invasive urinary bladder cancer treated with radical cystectomy. Int Urol Nephrol 40: 321-327, 2008. 
20. Kruger S, Weitsch G, Buttner H, et al: Overexpression of cerbB-2 oncoprotein in muscle-invasive bladder carcinoma: relationship with gene amplification, clinicopathological parameters and prognostic outcome. Int J Oncol 21: 981-987, 2002.

21. Sheehan KM, Sheahan K, O'Donoghue DP, MacSweeney F, Conroy RM, Fitzgerald DJ and Murray FE: The relationship between cyclooxygenase- 2 expression and colorectal cancer. JAMA 282: 1254-1257, 1999.

22. Grubbs CJ, Lubet RA, Koki AT, et al: Celecoxib inhibits Nbutyl-N-(4-hydroxybutyl)-nitrosamine-induced urinary bladder cancers in male B6D2F1 mice and female Fischer-344 rats. Cancer Res 60: 5599-5602, 2000

23. Castelao JE, Yuan JM, Gago-Dominguez M, Yu MC and Ross RK: Non-steroidal anti-inflammatory drugs and bladder cancer prevention. Br J Cancer 82: 1364-1369, 2000.

24. Shirahama T: Cyclooxygenase-2 expression is up-regulated in transitional cell carcinoma and its preneoplastic lesions in the human urinary bladder. Clin Cancer Res 6: 2424-2430, 2000.

25. Yu DS, Chen HI and Chang SY: The expression of cyclooxygenase in transitional cell carcinoma cell lines: its correlation with tumor differentiation, invasiveness and prostanoids production. Eur Urol 44: 491-494, 2003.
26. Shariat SF, Kim JH, Ayala GE, Kho K, Wheeler TM and Lerner SP: Cyclooxygenase-2 is highly expressed in carcinoma in situ and T1 transitional cell carcinoma of the bladder. J Urol 169: 938-942, 2003.

27. Shirahama T, Arima J, Akiba S and Sakakura C: Relation between cyclooxygenase- 2 expression and tumor invasiveness and patient survival in transitional cell carcinoma of the urinary bladder. Cancer 92: 188-193, 2001.

28. Kim SI, Kwon SM, Kim YS and Hong SJ: Association of cyclooxygenase-2 expression with prognosis of stage $\mathrm{T} 1$ grade 3 bladder cancer. Urology 60: 816-821, 2002.

29. Dovedi SJ, Kirby JA, Davies BR, Leung H and Kelly JD: Celecoxib has potent antitumour effects as a single agent and in combination with BCG immunotherapy in a model of urothelial cell carcinoma. Eur Urol 54: 621-630, 2008.

30. Eltze E, Wulfing C, von Struensee D, Piechota H, Buerger H and Hertle L: Cox-2 and HER2/neu co-expression in invasive bladder cancer. Int J Oncol 26: 1525-1531, 2005. 